\title{
An update analysis of two polymorphisms in encoding ribonuclease $L$ gene and prostate cancer risk: involving 13,372 cases and 11,953 controls
}

\author{
Yuan-Yuan Mi $\cdot$ Li-Jie Zhu $\cdot$ Sheng Wu • \\ Ning-Han Feng
}

Received: 8 June 2010/Accepted: 28 March 2011/Published online: 17 April 2011

(C) Springer-Verlag 2011

\begin{abstract}
Encoding ribonuclease L (RNASEL) is a ubiquitously expressed latent endoribonuclease involved in the mediation of antiviral and pro-apoptotic activities of the interferon-inducible 2-5A system. Although the relationship between RNASEL gene polymorphisms and prostate cancer (PCa) risk has been widely reported, results were somewhat controversial and underpowered. Now, we performed an update analysis of 14 publications evaluating the association between RNASEL R462Q and D541E polymorphisms and PCa risk. We conducted a literature search of PubMed database to identify all eligible articles that examined the association of RNASEL R462Q and D541E polymorphisms with $\mathrm{PCa}$. Odds ratios (OR) with $95 \%$ confidence intervals (CI) were estimated to assess these association. R462Q showed a significantly elevated effect on Africans (QQ vs. RR: $\mathrm{OR}=2.50,95 \% \mathrm{CI}=1.28-4.87$, $\left.P_{\text {heterogeneity }}=0.231\right)$. In addition, PCa men who contain 462Q genotype had a higher Gleason score $\geq 7(\mathrm{OR}=1.16$, $\left.95 \% \mathrm{CI}=1.05-1.28, P_{\text {heterogeneity }}=0.906\right)$. On the other hand, D541E was associated with increased total PCa. In the stratified analysis by race, there was also significantly increased PCa in Africans and Caucasians, as well as in sporadic PCa studies $(\mathrm{OR}=1.09,95 \% \mathrm{CI}=1.04-1.15$, $P_{\text {heterogeneity }}=0.078$ ). Our update analysis showed evidence
\end{abstract}

Y.-Y. Mi ( $\varangle)$ · L.-J. Zhu $(\bowtie) \cdot$ S. Wu

Department of Urology, Third Affiliated Hospital of Nantong

University, 585 Xingyuan Road, 214041 Wuxi, China

e-mail: miyuanyuan1984@gmail.com

L.-J. Zhu

e-mail: miniao1984@163.com

N.-H. Feng

Department of Urology,

First Affiliated Hospital of Nanjing Medical University,

300 Guangzhou Road, 210029 Nanjing, China that RNASEL R462Q and D541E polymorphisms were associated with PCa risk. Still more well-designed studies should be performed to clarify the role of these two polymorphisms in the development of PCa.

Keywords RNASEL P Polymorphism - Prostate cancer . Gleason score · Development

\section{Introduction}

Prostate cancer ( $\mathrm{PCa}$ ) remains the most commonly diagnosed solid tumor and the second leading cause of cancer deaths among men in USA (Jemal et al. 2009). Many factors are known to contribute to the risk of $\mathrm{PCa}$, including diet, race/ethnicity, age, and sexual history (Hayes et al. 2000; Kolonel 2001; Chan and Giovannucci 2001); however, family history is the single most significant and reproducible risk factor, where men with two or three first-degree relatives with PCa had a 5- and 11-fold increased risk of developing PCa, respectively (Steinberg et al. 1990). Chronic inflammation may play a role in the etiology of PCa. Some epidemiological evidence suggests that sexually transmitted infections and prostatitis increase the risk of $\mathrm{PCa}$, while aspirin and other anti-inflammatory agents have been inversely associated with this disease (Mahmud et al. 2004).

The encoding ribonuclease $\mathrm{L}$ (RNASEL) has recently been proposed as a candidate for the hereditary prostate cancer (HPC1) gene, which locates on chromosome 1q2425 and comprises 741 amino acids. A strong candidate gene linked to the $H P C l$ region is $2^{\prime}-5^{\prime}$-oligoadenylatedependent RNASEL (Grönberg et al. 1997; Xu et al. 2001), which is a constitutively expressed latent endoribonuclease mediating the antiviral and proapoptotic activity of the 
interferon-inducible 2-5A system, and has been shown to play a role in regulating cellular viral defense, singlestranded RNA cleavage, tumor suppressor activities as stress-mediated apoptosis, cell proliferation, and regulation of protein synthesis (Le Roy et al. 2005; Xiang et al. 2003).

Several variants in RNASEL (E262X, 47delAAAG, $\mathrm{R} 462 \mathrm{Q}, \mathrm{D} 541 \mathrm{E})$ have been investigated in relation to familiar and sporadic PCa (Casey et al. 2002; Wiklund et al. 2004). Some families also carried relatively two common RNASEL variants: $1385 \mathrm{G} \rightarrow \mathrm{A}$; rs486907 (resulting in the aminoacid substitution R462Q) and 1623T $\rightarrow \mathrm{G}$; rs627928 (resulting in the aminoacid substitution D541E) (Carpten et al. 2002). Both variants have been found to be significantly associated with PCa risk albeit with betweenstudy variability in outcome. The R462Q polymorphism reduces the ability of cell to cause apoptosis in response to activation by $2-5 \mathrm{~A}$ and causes a threefold reduction in enzymatic activity, whereas the D541E variant has similar enzymatic activity as wild-type RNASEL (Casey et al. 2002). Previously, Li and Tai (2006) performed a meta-analysis of the association of these two polymorphisms in RNASEL and $\mathrm{PCa}$ risk and found that compared with the genotype D/D, the E variant at the D541E polymorphism increases PCa risk by $<2$-fold in Caucasians. In the last 5 years, a number of new case-control studies have been published, so an update analysis is necessary to carry out.

So far, there are thirteen case-control studies in 11 articles (Wiklund et al. 2004; Agalliu et al. 2010; Robbins et al. 2008; Shea et al. 2008; Shook et al. 2007; Daugherty et al. 2007; Cybulski et al. 2007; Nam et al. 2005; Maier et al. 2005; Wang et al. 2002; Rökman et al. 2002) involving the role of R462Q polymorphism, and also thirteen studies in 11 articles (Wiklund et al. 2004; Robbins et al. 2008; Shea et al. 2008; Shook et al. 2007; Cybulski et al. 2007; Wang et al. 2002; Rökman et al. 2002; Beuten et al. 2010; NoonanWheeler et al. 2006; Nakazato et al. 2003) investigated the role of D541E polymorphism on the risk of PCa.

Taking into consideration of the extensive role of RNASEL in PCa, a more precise estimation of the association of R462Q and D541E polymorphisms in RNASEL and PCa risk is derived, we performed a meta-analysis of all eligible case-control studies.

\section{Materials and methods}

Publication search

We attempted to include all the case-control studies published to date on the association between RNASEL gene polymorphisms and PCa risk. Eligible studies were identified by searching the electronic literature PubMed for relevant reports (the range of publication years was from 2000 to
2011, using the search terms "RNASEL" or "ribonuclease L", "polymorphism" or "variant" and "prostate cancer" or "prostate"). A total of 70 articles were retrieved, of which 14 articles according to the inclusion criteria reported on studies examining the association between RNASEL R462Q and D541E polymorphisms and PCa risk.

\section{Inclusion criteria}

Inclusion criteria contains the following: (1) evaluation of RNASEL R462Q and/or D541E polymorphisms and $\mathrm{PCa}$ risk; (2) case-control studies; (3) genotype frequency was available; (4) the study was published in English language; (5) only the full-text manuscripts were included; and (6) Hardy-Weinberg equilibrium (HWE) of controls were more than 0.05 .

\section{Exclusion criteria}

Major exclusion criteria are as follows: (1) no control population; (2) no available genotype frequency; (3) HWE of controls were less than 0.05 ; (4) if two or more studies used the same data or duplicated with each other, we included the latest one and excluded others; and (5) studies have not been published.

\section{Data extraction}

Data were extracted from each study by three authors (YuanYuan Mi, Li-Jie Zhu, and Sheng Wu) independently according to the prespecified inclusion criteria. Data extracted from these articles included: first author's last name, year of publication, country of origin, research race, source of control (population-based, PB and hospital-based, HB), sample size (case/control), and HWE value of controls.

Statistical analysis

Odds ratios (ORs) with $95 \%$ confidence intervals (CIs) were used to measure the strength of the relationship between RNASEL R462Q and/or D541E polymorphism and $\mathrm{PCa}$ risk based on the genotype frequencies in cases and controls. In our analysis, we recognized $462 \mathrm{Q}$ or $541 \mathrm{E}$ as 'M', and R462 or D541 as 'W'. We explored the association between R462Q or D541E and PCa risk using three different models: allelic contrast (M vs. W), heterozygote comparison (MW vs. WW) as well as homozygote comparison (MM vs. WW) and dominant model (MM + MW vs. WW), respectively. Subgroup analysis was performed by race, source of case, Gleason score, and tumor stage. Different ethnic descents are categorized as Caucasian, Asian, African, and Mixed (if included population is not pure race). Source of case group contains familial and 
sporadic origin in PCa. Familial PCa represents families in which there are two first-degree or one first-degree and two or more second-degree relatives with PCa. Disease aggressiveness was defined as "Low" (T category $<\mathrm{T} 2 \mathrm{c}$ and/or Gleason score $<7$ ) or "High" ( $\mathrm{T}$ category $\geq \mathrm{T} 2 \mathrm{c}$ and/or Gleason score $\geq 7$ ).

The fixed effects model (Mantel and Haenszel 1959) and the random effects model (DerSimonian and Laird 1986) were used to calculate the pooled OR. Heterogeneity assumption was evaluated with a chi-square-based $Q$ test among the studies and at the same time, the statistical significance of the summary OR was determined with the $Z$ test. A $P$ value of more than 0.05 for the $Q$ test indicated a lack of heterogeneity among the studies and fixed effects model was used, otherwise, random effects model was used. The departure of frequencies of RNASEL polymorphisms from expectation under HWE was assessed by $\chi^{2}$ test in controls, $P<0.05$ was considered significant. Publication bias was assessed with Egger's test (1997). All statistical tests for this meta-analysis were performed with Stata software (version 10.0; StataCorp LP, College Station, TX).

\section{Results}

\section{Study inclusion}

From all 70 abstracts retrieved through the search criteria in PubMed, 56 were excluded (including duplication, review, meta-analysis, case-only, and insufficient genotype). Finally, we identified 14 articles (29 case-control studies) to evaluate the association of RNASEL of R462Q and/or D541E polymorphisms with risk for PCa. Study characteristics were given in Table 1. According to the inclusion criteria, three case-control studies were excluded as their HWE was $<0.05$. (Shook et al. 2007; Beuten et al. 2010; Nakazato et al. 2003). Therefore, there were fifteen publications involving 13,372 cases and 11,953 controls. Control population included study participants with a normal digital rectal examination (DRE) and serum prostate-specific antigen (PSA) values of $<4 \mathrm{ng}$ / $\mathrm{ml}$, as well as age-matched men, without individual or family history of cancer. For the R462Q polymorphism, Q\% in Mixed $(31.6 \%)$ or Caucasian $(36.6 \%)$ was higher than in African (13.3\%) in cases. There were 8 studies of Caucasian, 4 of African and one of Mixed population. Four studies referred to Gleason score and 3 studies about $\mathrm{T}$ stage in 3 different articles (Agalliu et al. 2010; Wang et al. 2002; Nakazato et al. 2003). Eight studied came from familial source and 7 from sporadic. For the D541E polymorphism, $\mathrm{E} \%$ in Asian (66.3\%) was higher than in Caucasian (55.2\%) or African (34.5\%) in cases. There had 9 studies of Caucasian, 3 of African and one of Asian. Ten studied came from familial source and 6 from sporadic. Just only one article (Nakazato et al. 2003) contained the detail in Gleason score and T stage. In another study (Larson et al. 2008), the author got Gleason score and T stage together as "Low-" or "High" risk subgroups, which was excluded because of insufficient available data.

Table 1 Study characteristics from published studies on the relationship between two polymorphisms in RNASEL gene and prostate cancer

\begin{tabular}{|c|c|c|c|c|c|c|c|}
\hline \multirow[t]{2}{*}{ Author/year } & \multirow[t]{2}{*}{ Country } & \multirow[t]{2}{*}{ Race } & \multicolumn{2}{|l|}{ Case/control } & \multicolumn{2}{|c|}{ HWE of control } & \multirow[t]{2}{*}{ Source of control } \\
\hline & & & R462Q & D541E & R462Q & D541E & \\
\hline Agalliu et al. (2010) & USA & Caucasian & $965 / 1,237$ & - & 0.137 & - & $\mathrm{PB}$ \\
\hline Beuten et al. (2010) & USA & Caucasian & - & $156 / 227$ & - & 0.368 & $\mathrm{HB}$ \\
\hline Robbins et al. (2008) & USA & African & $243 / 296$ & $243 / 296$ & 0.95 & 0.495 & $\mathrm{HB}$ \\
\hline Shea et al. (2008) & USA & African & $230 / 452$ & $230 / 458$ & 0.168 & 0.496 & PB \\
\hline Shook et al. (2007) & USA & Caucasian & $430 / 484$ & - & - & 0.187 & $\mathrm{HB}$ \\
\hline Shook et al. (2007) & USA & Caucasian & $430 / 503$ & $150 / 242$ & 0.981 & 0.525 & HB \\
\hline Shook et al. (2007) & USA & African & $68 / 145$ & $68 / 146$ & 0.633 & 0.661 & $\mathrm{HB}$ \\
\hline Daugherty et al. (2007) & USA & African & $98 / 380$ & - & 0.261 & - & PB \\
\hline Daugherty et al. (2007) & USA & Caucasian & $1,116 / 1,344$ & - & 0.235 & - & $\mathrm{PB}$ \\
\hline Cybulski et al. (2007) & Canada & Caucasian & $737 / 511$ & $737 / 511$ & 0.625 & 0.344 & PB \\
\hline Noonan-Wheeler et al. (2006) & USA & Caucasian & - & $150 / 170$ & - & 0.198 & $\mathrm{HB}$ \\
\hline Nam et al. (2005) & Canada & Mixed & $996 / 1,092$ & - & 0.464 & - & PB \\
\hline Maier et al. (2005) & Germany & Caucasian & $363 / 207$ & $363 / 207$ & 0.629 & 0.514 & $\mathrm{HB}$ \\
\hline Wiklund et al. (2004) & Sweden & Caucasian & $1,622 / 796$ & $1,563 / 791$ & 0.432 & 0.199 & PB \\
\hline Nakazato et al. (2003) & Japan & Asian & - & $101 / 105$ & - & 0.138 & PB \\
\hline Wang et al. (2002) & USA & Caucasian & $918 / 493$ & $929 / 508$ & 0.802 & 0.515 & HB \\
\hline Rökman et al. (2002) & USA & Caucasian & $233 / 176$ & $233 / 176$ & 0.745 & 0.434 & PB \\
\hline
\end{tabular}


Meta-analysis

In total, individuals carrying the QQ genotype did not have significantly increased risk of $\mathrm{PCa}$ in all three models (Table 2). However, stratified analysis by race, RNASEL R462Q polymorphism was strongly associated with PCa risk under homozygote comparison in African populations $(\mathrm{OR}=2.50,95 \% \mathrm{CI}=1.28-4.87, P=0.231$ for heterogeneity). In the subgroup analysis by source of case also, no association was detected in familial or sporadic $\mathrm{PCa}$ (Table 2). Interestingly, 462Q allele had a weekly higher percentage value than R462 allele in subgroup of Gleason score $\geq 7(\mathrm{OR}=1.16,95 \% \mathrm{CI}=1.05-1.28, P=0.906$ for heterogeneity, $P=0.005$; Table 3 ).

In overall analysis, the 541E allele was associated with increased PCa risk compared with those with the D541 allele $(\mathrm{OR}=1.04,95 \% \mathrm{CI}=1.01-1.07, P=0.164$ for heterogeneity), as well as heterozygote comparison $(\mathrm{OR}=1.07$,
$95 \% \mathrm{CI}=1.02-1.13, P=0.059$ for heterogeneity). Specifically, 541E significantly increased PCa risk in Caucasian and African race in several models, for example: in Caucasian, $\mathrm{OR}=1.04,95 \% \mathrm{CI}=1.01-1.07$ for $\mathrm{M}$ versus $\mathrm{W}$; in African, $\mathrm{OR}=1.49,95 \% \mathrm{CI}=1.11-2.00$ for $\mathrm{MW}$ versus WW; Table 2. In the source of case subgroup, we found a weekly increased association between D541E polymorphism and sporadic $\mathrm{PCa}(\mathrm{OR}=1.09,95 \% \mathrm{CI}=1.04-1.15$, $P=0.078$ for heterogeneity; Table 2).

Sensitivity analysis and bias diagnosis

We use sensitivity analysis to determine whether modification of the inclusion criteria of the meta-analysis affected the final results. Finally, no other single study influenced the summary OR qualitatively as indicated by sensitivity analysis. The Egger's test was performed to access the publication bias of literatures, which was used to provide

Table 2 Total and stratified analysis of two polymorphisms in RNASEL gene on prostate cancer

\begin{tabular}{|c|c|c|c|c|c|c|c|c|}
\hline \multirow[t]{2}{*}{ Variables } & \multirow[t]{2}{*}{$N$} & \multirow[t]{2}{*}{ Case/control } & \multicolumn{2}{|l|}{$M$ versus $W$} & \multicolumn{2}{|l|}{ MM versus WW } & \multicolumn{2}{|c|}{$\mathrm{MM}+\mathrm{MW}$ versus $\mathrm{WW}$} \\
\hline & & & OR $(95 \% \mathrm{CI})$ & $P_{\mathrm{h}}$ & OR $(95 \% \mathrm{CI})$ & $P_{\mathrm{h}}$ & OR $(95 \% \mathrm{CI})$ & $P_{\mathrm{h}}$ \\
\hline \multicolumn{9}{|l|}{$R 462 Q$} \\
\hline Total & 13 & $8,019 / 7,632$ & $1.00(0.97-1.03)$ & 0.322 & $1.02(0.94-1.10)$ & 0.217 & $0.99(0.96-1.02)$ & 0.932 \\
\hline \multicolumn{9}{|l|}{ Race } \\
\hline Caucasian & 8 & $6,384 / 5,267$ & $0.99(0.96-1.03)$ & 0.733 & $0.99(0.90-1.08)$ & 0.643 & $0.99(0.96-1.02)$ & 0.912 \\
\hline African & 4 & $639 / 1,273$ & $1.10(0.92-1.32)$ & 0.056 & $2.50(1.28-4.87)$ & 0.231 & $1.03(0.86-1.22)$ & 0.433 \\
\hline Mixed & 1 & $996 / 1,092$ & $1.01(0.89-1.16)$ & - & $1.07(0.80-1.43)$ & - & $0.99(0.84-1.18)$ & - \\
\hline \multicolumn{9}{|c|}{ Source of case } \\
\hline Sporadic & 7 & $3,895 / 4,122$ & $1.01(0.97-1.05)$ & 0.945 & $1.04(0.92-1.16)$ & 0.923 & $1.00(0.97-1.04)$ & 0.824 \\
\hline Familial & 8 & $1,877 / 2,791$ & $0.99(0.84-1.17)$ & 0.007 & $1.03(0.69-1.56)$ & 0.002 & $0.97(0.92-1.02)$ & 0.315 \\
\hline \multirow[t]{2}{*}{ Variables } & \multirow[t]{2}{*}{$N$} & \multirow[t]{2}{*}{ Case/control } & \multicolumn{2}{|l|}{$M$ versus $W$} & \multicolumn{2}{|l|}{ MW versus WW } & \multicolumn{2}{|c|}{$\mathrm{MM}+\mathrm{MW}$ versus $\mathrm{WW}$} \\
\hline & & & OR $(95 \% \mathrm{CI})$ & $P_{\mathrm{h}}$ & OR $(95 \% \mathrm{CI})$ & $P_{\mathrm{h}}$ & OR $(95 \% \mathrm{CI})$ & $P_{\mathrm{h}}$ \\
\hline \multicolumn{9}{|l|}{ D541E } \\
\hline Total & 13 & $5,353 / 4,321$ & $1.04(1.01-1.07)$ & 0.164 & $1.07(1.02-1.13)$ & 0.059 & $1.02(1.00-1.05)$ & 0.065 \\
\hline \multicolumn{9}{|l|}{ Race } \\
\hline Caucasian & 9 & $4,711 / 3,316$ & $1.04(1.01-1.07)$ & 0.828 & $1.07(1.01-1.13)$ & 0.742 & $1.03(1.00-1.05)$ & 0.396 \\
\hline African & 3 & $541 / 900$ & $1.13(1.01-1.26)$ & 0.458 & $1.49(1.11-2.00)$ & 0.433 & $1.06(0.96-1.17)$ & 0.699 \\
\hline Asian & 1 & $101 / 105$ & $0.60(0.39-0.92)$ & - & $0.14(0.04-0.52)$ & - & $0.14(0.04-0.48)$ & - \\
\hline \multicolumn{9}{|c|}{ Source of case } \\
\hline Sporadic & 6 & $2,305 / 2,148$ & $1.24(0.87-1.76)$ & 0.000 & $1.09(1.04-1.15)$ & 0.078 & $1.43(0.97-2.10)$ & 0.000 \\
\hline Familial & 10 & $1,864 / 3,012$ & $1.27(0.98-1.65)$ & 0.000 & $1.01(0.72-1.42)$ & 0.000 & $1.18(0.83-1.68)$ & 0.000 \\
\hline
\end{tabular}

Table 3 Relationship between R462Q polymorphism in RNASEL gene and prostate cancer prognosis

\begin{tabular}{llllllll}
\hline RNASEL & Allele & Gleason $\geq 7$ & Gleason $<7$ & OR $(95 \% \mathrm{CI})$ & $P_{\mathrm{h}}$ & $P$ & Egger's test \\
\hline R462Q & $\mathrm{R}$ & 891 & 1,496 & & & \\
& $\mathrm{Q}$ & 435 & 644 & $1.16(1.05-1.28)$ & 0.906 & 0.005 & $t=0.81, P=0.504$ \\
\hline
\end{tabular}


statistical evidence of funnel plot symmetry. Ultimately, the results did not suggest any evidence of publication bias (data not show).

\section{Discussion}

RNASEL is a constitutively expressed latent endoribonclease that mediates the antiviral and proapoptotic activities of the IFN-inducible 2-5A system. There is a strong biological plausibility for the involvement of the RNASEL gene in $\mathrm{PCa}$, since mutation carriers in this gene exhibited loss of heterozygosity and as a consequence were deficient in functional RNase L activity (Carpten et al. 2002). The rapid growth of $R N A S E L$ genetics creates countless opportunities for studies to explore this disease association. In the present meta-analysis, 13,372 cases and 11,953 controls concerning the R462Q D541E polymorphism in the protein kinase region of RNASEL, 5,353 cases and 4,321 controls concerning D541E polymorphism in the ribonuclease domain of RNASEL were included, respectively.

Although no significant associations were observed between $\mathrm{R} 462 \mathrm{Q}$ polymorphism and the susceptibility to $\mathrm{PCa}$ in overall analysis, weak but significant relationship was detected in Africans. RNASEL R462Q polymorphism was implicated in up to $13 \%$ of PCa cases, with 3 times less enzymatic activity than the wild type, and an association among Caucasians and Africans with sporadic PCa risk was found (Casey et al. 2002). Our results suggested that RNASEL R462Q polymorphism was associated with $\mathrm{PCa}$ risk in African population rather than in Caucasians, which confirmed the hypothesis described above. Gleason score and $\mathrm{T}$ stage could be considered as prognostic factors in $\mathrm{PCa}$, if Gleason score is more than 7 or $\mathrm{T}$ stage is higher than T2c, individuals must have a worse prognosis and PCa will show more aggressive. In our study, we found individuals who carried 462Q allele had a high percentage in Gleason $\geq 7$, manifesting that $\mathrm{R} 462 \mathrm{Q}$ polymorphism was partly related to $\mathrm{PCa}$ outcome. We did not find any association between $\mathrm{T}$ stage and PCa (data not show).

For D541E polymorphism, although this variant had similar enzymatic activity as wild-type RNASEL and could not influence its enzyme (Casey et al. 2002), whose function or mechanism has not been detected, a significant relationship with $\mathrm{PCa}$ was detected in Caucasians, the same as Li and Tai (2006); moreover, a new association between Africans and D541E polymorphism was observed in two genetic models. It is well known that sporadic and familial $\mathrm{PCa}$ have frequently quite different epidemiological and molecular peculiarities, clinical evolution and prognosis, so it is better to study these two kinds of $\mathrm{PCa}$, respectively.
Initially, researchers discovered the RNASEL gene is one of the major candidate genes for PCa, since mutations in this gene were linked to PCa in high-risk hereditary PCa families (Carpten et al. 2002). However, also poorly significant association was found in sporadic, but not in familial PCa and D541E polymorphism. The only Asian study (Nakazato et al. 2003) found decreased familial PCa risk in Japanese with the genotype EE. Larger studies involving a wider spectrum of Asian people are needed for a more definitive evaluation of the relationship between D541E polymorphism and $\mathrm{PCa}$ risk in Asians.

Several limitations of this meta-analysis should be addressed. First of all, there were only one Mixed casecontrol study about R462Q polymorphism and also one Asian population study about D541E polymorphism. Further, more new studies should focus on these two aspects. Second, the interactions between gene-gene, gene-environment, and even different polymorphic loci of the same gene may modulate $\mathrm{PCa}$; future analysis may include these factors. Third, four studies referred to Gleason score and 3 studies about $\mathrm{T}$ stage about R462Q and one article contained the detail in Gleason score and $\mathrm{T}$ stage about D541E, the number of which was small; further studies should increase these relations to enlarge the subsequent meta-analysis. In spite of these, our meta-analysis also had four advantages. First, substantial number of cases and controls were pooled from different studies, which significantly increased statistical power of the analysis. Second, the quality of case-control studies included in the current meta-analysis was satisfactory based on our selection criteria. Third, the HWE of controls were all more than 0.05. Fourth, publication bias was not detected in all genetic models.

In summary, present update analysis found novel evidence that RNASEL R462Q or D541E polymorphism could increase $\mathrm{PCa}$ risk in Africans, moreover, $\mathrm{R} 462 \mathrm{Q}$ polymorphism was associated with $\mathrm{PCa}$ prognosis. Further prospective studies with larger numbers of worldwide individuals are expected to examine associations between these two polymorphisms in RNASEL and PCa.

Conflict of interest The authors declare no conflict of interests.

\section{References}

Agalliu I, Leanza SM, Smith L, Trent JM, Carpten JD, Bailey-Wilson JE, Burk RD (2010) Contribution of HPC1 (RNASEL) and HPCX variants to prostate cancer in a founder population. Prostate 70:1716-1727

Beuten J, Gelfond JA, Franke JL, Shook S, Johnson-Pais TL, Thompson IM, Leach RJ (2010) Single and multivariate associations of MSR1, ELAC2, and RNASEL with prostate cancer in an ethnic diverse cohort of men. Cancer Epidemiol Biomarkers Prev 19:588-599 
Carpten J, Nupponen N, Isaacs S, Sood R, Robbins C, Xu J, Faruque M, Moses T, Ewing C, Gillanders E, Hu P, Bujnovszky P, Makalowska I, Baffoe-Bonnie A, Faith D, Smith J, Stephan D, Wiley K, Brownstein M, Gildea D, Kelly B, Jenkins R, Hostetter G, Matikainen M, Schleutker J, Klinger K, Connors T, Xiang Y, Wang Z, De Marzo A, Papadopoulos N, Kallioniemi OP, Burk R, Meyers D, Grönberg H, Meltzer P, Silverman R, BaileyWilson J, Walsh P, Isaacs W, Trent J (2002) Germline mutations in the ribonuclease $\mathrm{L}$ gene in families showing linkage with HPC1. Nat Genet 30:181-184

Casey G, Neville PJ, Plummer SJ, Xiang Y, Krumroy LM, Klein EA, Catalona WJ, Nupponen N, Carpten JD, Trent JM, Silverman RH, Witte JS (2002) RNASEL Arg462Gln variant is implicated in up to $13 \%$ of prostate cancer cases. Nat Genet 32:581-583

Chan JM, Giovannucci EL (2001) Dairy products, calcium, and vitamin D and risk of prostate cancer. Epidemiol Rev 23:87-92

Cybulski C, Wokołorczyk D, Jakubowska A, Gliniewicz B, Sikorski A, Huzarski T, Debniak T, Narod SA, Lubiński J (2007) A variation in MSR1, RNASEL and E-cadherin genes and prostate cancer in Poland. Urol Int 79:44-49

Daugherty SE, Hayes RB, Yeager M, Andriole GL, Chatterjee N, Huang WY, Isaacs WB, Platz EA (2007) RNASEL Arg462Gln polymorphism and prostate cancer in PLCO. Prostate 67:849-854

DerSimonian R, Laird N (1986) Meta-analysis in clinical trials. Control Clin Trials 7:177-188

Egger M, Davey Smith G, Schneider M, Minder C (1997) Bias in metaanalysis detected by a simple, graphical test. BMJ 315:629-634

Grönberg H, Xu J, Smith JR, Carpten JD, Isaacs SD, Freije D, Bova GS, Danber JE, Bergh A, Walsh PC, Collins FS, Trent JM, Meyers DA, Isaacs WB (1997) Early age at diagnosis in families providing evidence of linkage to the hereditary prostate cancer locus (HPC1) on chromosome 1. Cancer Res 57:4707-4709

Hayes RB, Pottern LM, Strickler H, Rabkin C, Pope V, Swanson GM, Greenberg RS, Schoenberg JB, Liff J, Schwartz AG, Hoover RN, Fraumeni JF Jr (2000) Sexual behaviour, STDs and risks for prostate cancer. Br J Cancer 82:718-725

Jemal A, Siegel R, Ward E, Hao Y, Xu J, Thun MJ (2009) Cancer statistics, 2009. CA Cancer J Clin 59:225-249

Kolonel LN (2001) Fat, meat, and prostate cancer. Epidemiol Rev 23:72-81

Larson BT, Magi-Galluzzi C, Casey G, Plummer SJ, Silverman R, Klein EA (2008) Pathological aggressiveness of prostatic carcinomas related to RNASEL R462Q allelic variants. J Urol 179:1344-1348

Le Roy F, Salehzada T, Bisbal C, Dougherty JP, Peltz SW (2005) A newly discovered function for RNase $\mathrm{L}$ in regulating translation termination. Nat Struct Mol Biol 12:505-512

Li H, Tai BC (2006) RNASEL gene polymorphisms and the risk of prostate cancer: a meta-analysis. Clin Cancer Res 12:5713-5719

Mahmud S, Franco E, Aprikian A (2004) Prostate cancer and use of nonsteroidal anti-inflammatory drugs: systematic review and meta-analysis. Br J Cancer 90:93-99

Maier C, Haeusler J, Herkommer K, Vesovic Z, Hoegel J, Vogel W, Paiss $T$ (2005) Mutation screening and association study of RNASEL as a prostate cancer susceptibility gene. Br J Cancer 92:1159-1164
Mantel N, Haenszel W (1959) Statistical aspects of the analysis of data from retrospective studies of disease. J Natl Cancer Inst 22:719-748

Nakazato H, Suzuki K, Matsui H, Ohtake N, Nakata S, Yamanaka H (2003) Role of genetic polymorphisms of the RNASEL gene on familial prostate cancer risk in a Japanese population. $\mathrm{Br} \mathrm{J}$ Cancer 89:691-696

Nam RK, Zhang WW, Jewett MA, Trachtenberg J, Klotz LH, Emami M, Sugar L, Sweet J, Toi A, Narod SA (2005) The use of genetic markers to determine risk for prostate cancer at prostate biopsy. Clin Cancer Res 11:8391-8397

Noonan-Wheeler FC, Wu W, Roehl KA, Klim A, Haugen J, Suarez BK, Kibel AS (2006) Association of hereditary prostate cancer gene polymorphic variants with sporadic aggressive prostate carcinoma. Prostate 66:49-56

Robbins CM, Hernandez W, Ahaghotu C, Bennett J, Hoke G, Mason T, Pettaway CA, Vijayakumar S, Weinrich S, Furbert-Harris P, Dunston G, Powell IJ, Carpten JD, Kittles RA (2008) Association of HPC2/ELAC2 and RNASEL non-synonymous variants with prostate cancer risk in African American familial and sporadic cases. Prostate 68:1790-1797

Rökman A, Ikonen T, Seppälä EH, Nupponen N, Autio V, Mononen N, Bailey-Wilson J, Trent J, Carpten J, Matikainen MP, Koivisto PA, Tammela TL, Kallioniemi OP, Schleutker J (2002) Germline alterations of the RNASEL gene, a candidate HPC1 gene at 1q25, in patients and families with prostate cancer. Am J Hum Genet 70:1299-1304

Shea PR, Ishwad CS, Bunker CH, Patrick AL, Kuller LH, Ferrell RE (2008) RNASEL and RNASEL-inhibitor variation and prostate cancer risk in Afro-Caribbeans. Prostate 68:354-359

Shook SJ, Beuten J, Torkko KC, Johnson-Pais TL, Troyer DA, Thompson IM, Leach RJ (2007) Association of RNASEL variants with prostate cancer risk in Hispanic Caucasians and African Americans. Clin Cancer Res 13:5959-5964

Steinberg GD, Carter BS, Beaty TH, Childs B, Walsh PC (1990) Family history and the risk of prostate cancer. Prostate 17:337-347

Wang L, McDonnell SK, Elkins DA, Slager SL, Christensen E, Marks AF, Cunningham JM, Peterson BJ, Jacobsen SJ, Cerhan JR, Blute ML, Schaid DJ, Thibodeau SN (2002) Analysis of the RNASEL gene in familial and sporadic prostate cancer. Am J Hum Genet 71:116-123

Wiklund F, Jonsson BA, Brookes AJ, Strömqvist L, Adolfsson J, Emanuelsson M, Adami HO, Augustsson-Bälter K, Grönberg H (2004) Genetic analysis of the RNASEL gene in hereditary, familial, and sporadic prostate cancer. Clin Cancer Res 10:7150-7156

Xiang Y, Wang Z, Murakami J, Plummer S, Klein EA, Carpten JD, Trent JM, Isaacs WB, Casey G, Silverman RH (2003) Effects of RNase L mutations associated with prostate cancer on apoptosis induced by $2^{\prime}, 5^{\prime}$-oligoadenylates. Cancer Res 63:6795-6801

Xu J, Zheng SL, Chang B, Smith JR, Carpten JD, Stine OC, Isaacs SD, Wiley KE, Henning L, Ewing C, Bujnovszky P, Bleeker ER, Walsh PC, Trent JM, Meyers DA, Isaacs WB (2001) Linkage of prostate cancer susceptibility loci to chromosome 1 . Hum Genet 108:335-345 